MATEC Web of Conferences 24,06005 (2015)

DOI: $10.1051 /$ matecconf/ 20152406005

C) Owned by the authors, published by EDP Sciences, 2015

\title{
Fuzzy Logic Controller Scheme for Floor Vibration Control
}

\author{
Donald Steve Nyawako1,a, Paul Reynolds ${ }^{1}$, Roberto Leal Pimentel ${ }^{2}$, Emma Hudson ${ }^{1}$ \\ 1 University of Exeter, Vibration Engineering Section, College of Engineering, Mathematics and Physical Sciences, UK. \\ 2 Federal University of Paraíba, Department of Civil and Environmental Engineering, 58051-900 João Pessoa, Brazil.
}

\begin{abstract}
The design of civil engineering floors is increasingly being governed by their vibration serviceability performance. This trend is the result of advancements in design technologies offering designers greater flexibilities in realising more lightweight, longer span and more open-plan layouts. These floors are prone to excitation from human activities. The present research work looks at analytical studies of active vibration control on a case study floor prototype that has been specifically designed to be representative of a real office floor structure. Specifically, it looks at tuning fuzzy control gains with the aim of adapting them to measured structural responses under human excitation. Vibration mitigation performances are compared with those of a general velocity feedback controller, and these are found to be identical in these sets of studies. It is also found that slightly less control force is required for the fuzzy controller scheme at moderate to low response levels and as a result of the adaptive gain, at very low responses the control force is close to zero, which is a desirable control feature. There is also saturation in the peak gain with the fuzzy controller scheme, with this gain tending towards the optimal feedback gain of the direct velocity feedback (DVF) at high response levels for this fuzzy design.
\end{abstract}

Keywords: vibration control, direct velocity feedback, floors, experimental modal analysis

\section{Introduction}

With the ever-increasing trends towards lightweight, longer-span and more open plan floor layouts, there are ongoing concerns towards their vibration serviceability performance. This is due to their lower modal frequencies and damping ratios, making them easily excitable by human walking. This can be annoying to the users of these facilities or be undesirable for the operation of sensitive equipment that require much lower vibration levels for their operation $[1,2]$.

For floor structures, there are design guidelines that specify desirable vibration serviceability performances, for example, in [3, 4, 5, 6]. In [3], for example, frequency weighted acceleration is used, and there are various curves relating to permissible acceleration levels in different floors with respect to their usage. When acceptable levels are exceeded, vibration mitigation technologies may be pursued to provide floors with enhanced vibration serviceability performance. Such technologies, which can be incorporated into the mainstream design process or as remedial measures for vibration serviceability problems can be categorised as passive, active, semi-active or hybrid techniques. There are various pros and cons relating to any approach

\footnotetext{
${ }^{\mathrm{a}}$ Corresponding author: d.s.nyawako@exeter.ac.uk
}

pursued in relation to set-up costs and achievable vibration mitigation performance.

This research focuses on active vibration control (AVC) technology. AVC technology, making use of collocated sensor and actuator pairs, and employing the direct velocity feedback (DVF) controller has been successfully implemented in field trials to enhance the vibration serviceability performance of some floors $[7,8$, 9]. Additional studies have looked into designing appropriate compensators to improve the robustness of the DVF controller [10].

Amidst the wide array of controllers available, which can be placed in various categories ranging from direct output feedback to model-based controllers, the fuzzy control scheme possesses some design freedoms that could be adapted, for example, to deal with different structural response levels. It has often been classified as an intelligent controller [11] and does not require an accurate model of the structure to be controlled. It was conceived by [12] and was originally presented not as a control methodology but as a way of processing data by allowing partial set membership rather than crisp set membership or non-membership. Since its conception, the fuzzy logic control design approach has been investigated in various studies. For example, the feasibility of fuzzy control towards structural control of a 
cantilever beam has been evaluated by [13] who have compared its performance with optimal control approaches. Desirable vibration mitigation performances have been obtained in their studies. In another case study, a fuzzy controller has been successfully developed for a hybrid mass damper system to attenuate translational vibrations of a framed prototype structure in any vertical plane. It employs an automatic directing system to identify the direction in which the structure vibrates so that the actuator can be rotated in that direction [14]. A further case study by [15] was based on developing a fuzzy controller for control of the dynamic response in building structures, and comparisons were made to an instantaneous optimal control method. It was found that the fuzzy controller can be adaptable for civil engineering structures. There is a vast quantity of other researches devoted to fuzzy control but only a few have been mentioned.

This work provides comparative studies of vibration mitigation performance between a direct velocity feedback (DVF) controller and a fuzzy controller scheme. The fuzzy controller is designed to adapt velocity gains to the responses of a prototype floor structure. Additionally, control forces, actuator mass displacement and velocity gains derived from the fuzzy controller for different sets of response levels are monitored.

\section{Floor prototype and experimental modal analysis tests}

Figure 1 is a photo of a reconfigurable floor prototype for which the present studies are based on. It comprises of two primary beams: $457 \times 191 \times 82 \mathrm{UB}$ spanning $7.5 \mathrm{~m}$, two edge beams: $305 \times 165 \times 40$ UB spanning $5.0 \mathrm{~m}$, an intermediary secondary beam: $203 \times 203 \times 60$ UC spanning $7.5 \mathrm{~m}$ and running parallel to the primary beams. The decking consists of twelve $1.25 \mathrm{~m} \times 2.5 \mathrm{~m}$ sandwich plate systems (SPS) that are bolted to the beams. Continuity between them is provided by $200 \times 12$ RHS beams, approximately $2.5 \mathrm{~m}$ in length and bolted underneath the SPS plates. Support points are four columns along each corner and with the primary beams resting on cylindrical rollers that allow rotation.

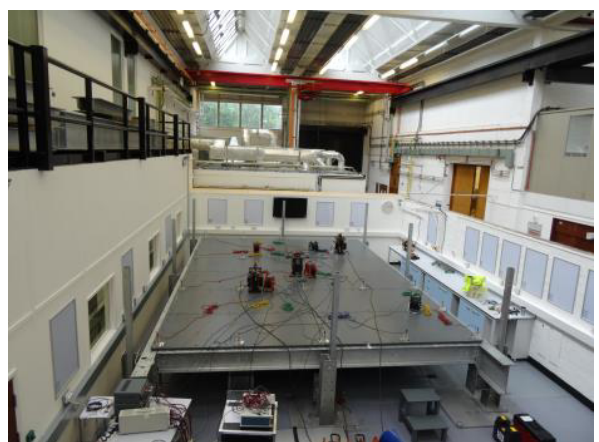

Figure 1. Photo of reconfigurable floor prototype

Experimental modal analysis (EMA) to evaluate the dynamic properties of the floor above was carried out with three excitation shakers located at TP12, TP18 and TP101 in Figure 3. These were driven by statistically uncorrelated random signals and their forces measured using three Endevco 7754A-1000 accelerometers attached to their inertial masses. Floor responses were measured with 19 QA-750 force balance accelerometers in two swipes and thus covering the desired grid of entire floor area. A Data Physics Mobilyzer II digital spectrum analyser was used for data acquisition, and force and vibration response data were sampled with a baseband setting of $80 \mathrm{~Hz}$. Figures $2 \mathrm{a}$ and $2 \mathrm{~b}$ show the point accelerance frequency response functions (FRFs) at the excitation locations.

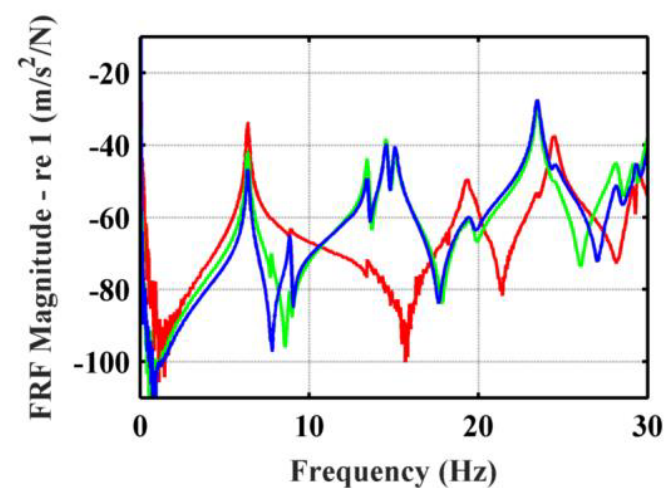

a)

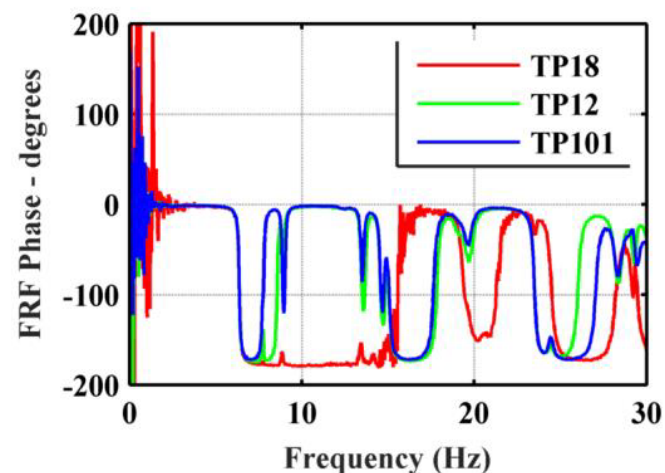

Figure 2. Point accelerance FRF magnitudes and phases at excitation locations

Table 1 shows some estimated modal properties of the floor prototype, i.e. modal frequencies and damping ratios of the identified vibration modes up to $25 \mathrm{~Hz}$. Figures $3 \mathrm{a}, 3 \mathrm{~b}$ and $3 \mathrm{c}$ show typical mode shapes corresponding to the $1^{\text {st }}, 6^{\text {th }}$ and $8^{\text {th }}$ vibration modes in Table 1.

Table 1. Summary of estimated modal properties

\begin{tabular}{|c|c|c|}
\hline Mode & $\begin{array}{c}\text { Natural Frequency } \\
{[\mathbf{H z}]}\end{array}$ & $\begin{array}{c}\text { Damping Ratio } \\
{[\mathbf{\%}]}\end{array}$ \\
\hline 1 & 6.35 & 0.9 \\
\hline 2 & 8.83 & 0.5 \\
\hline 3 & 13.4 & 0.6 \\
\hline 4 & 14.5 & 0.6 \\
\hline 5 & 15.0 & 0.8 \\
\hline 6 & 19.6 & 1.4 \\
\hline 7 & 23.5 & 0.5 \\
\hline 8 & 24.4 & 0.7 \\
\hline
\end{tabular}




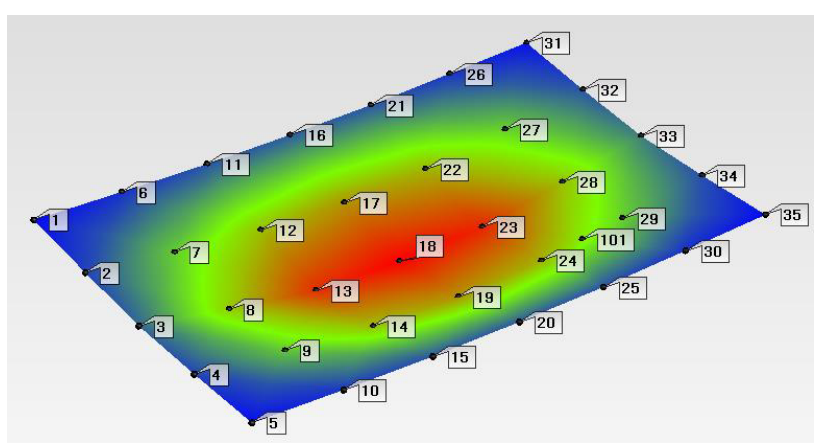

(a)

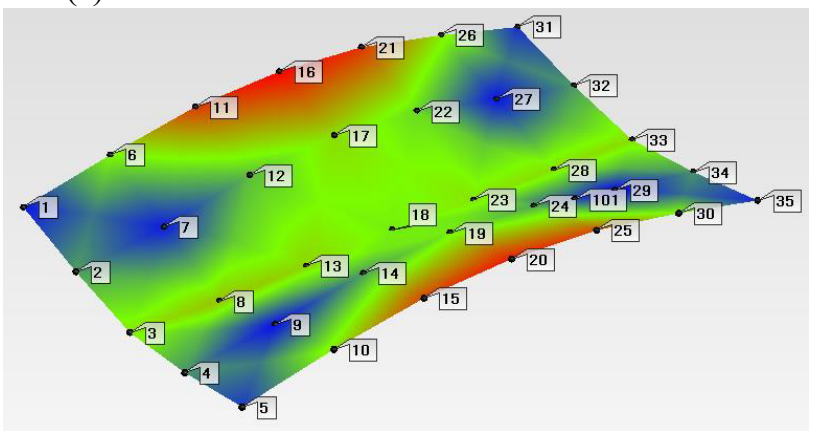

(b)

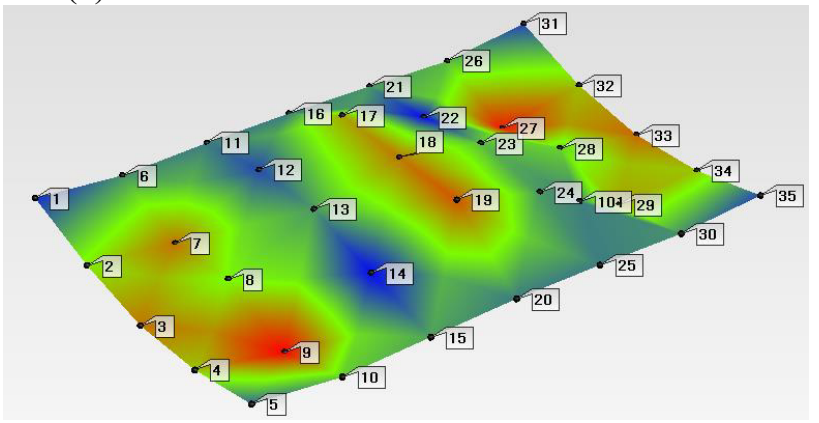

(c)

Figure 3. Typical mode shapes for floor prototype

\section{Reduced order model and controller designs}

A lumped parameter model of the floor prototype with $n$ modal co-ordinates is formulated as shown in Equation 1a, and the state space representations in Equations $1 \mathrm{~b}$ and $1 \mathrm{c}$ derived. These can be tailored to provide outputs in both modal or spatial velocities and accelerations and appropriate reduced-order models (ROM) can be extracted for the controller designs. $M^{*}$, $C^{*}$ and $K^{*}$ are the $n x n$ modal mass, modal damping and modal stiffness matrices, whilst $\phi$ is the mxn mass normalised modal transformation matrix. $D$ is the $m x m$ actuator location matrix and $E$ is the $m x m$ excitation force location matrix. $\zeta_{i}$ and $\omega_{i}$ are the modal damping ratio and natural circular frequency coefficients of the ith vibration mode.

$$
M^{*} \ddot{z}+C^{*} \dot{z}+K^{*} z=\phi^{T} D u+\phi^{T} E f
$$

$$
\begin{aligned}
& \left\{\begin{array}{l}
\dot{x}_{1} \\
\dot{x}_{2}
\end{array}\right\}=\left[\begin{array}{cc}
0 & I \\
-\frac{K^{*}}{M^{*}} & -\frac{C^{*}}{M^{*}}
\end{array}\right]\left\{\begin{array}{l}
x_{1} \\
x_{2}
\end{array}\right\}+\left[\begin{array}{cc}
0 & 0 \\
\phi^{T} D & \phi^{T} E
\end{array}\right]\left\{\begin{array}{l}
u \\
f
\end{array}\right\} \\
& \left\{\begin{array}{l}
y_{1} \\
y_{2}
\end{array}\right\}=\left[\begin{array}{cc}
0 & I \\
-\frac{K^{*}}{M^{*}} & -\frac{C^{*}}{M^{*}}
\end{array}\right]\left\{\begin{array}{l}
x_{1} \\
x_{2}
\end{array}\right\}+\left[\begin{array}{cc}
0 & 0 \\
\phi^{T} D & \phi^{T} E
\end{array}\right]\left\{\begin{array}{l}
u \\
f
\end{array}\right\}
\end{aligned}
$$

Where:

$$
\begin{aligned}
& M^{*}=\left[\begin{array}{cccc}
1 & 0 & \cdots & 0 \\
0 & 1 & \cdots & 0 \\
\vdots & \vdots & \ddots & \vdots \\
0 & 0 & \cdots & 1
\end{array}\right], \phi=\left[\begin{array}{cccc}
\phi_{1,1} & \phi_{1,2} & \cdots & \phi_{1,8} \\
\phi_{2,1} & \phi_{2,2} & \cdots & \phi_{2,8} \\
\vdots & \vdots & \ddots & \vdots \\
\phi_{36,1} & \phi_{36,2} & \cdots & \phi_{36,8}
\end{array}\right] \\
& K^{*}=\left[\begin{array}{cccc}
\omega_{1}^{2} & 0 & \cdots & 0 \\
0 & \omega_{2}^{2} & \cdots & 0 \\
\vdots & \vdots & \ddots & \vdots \\
0 & 0 & \cdots & \omega_{8}^{2}
\end{array}\right] \text {, } \\
& C^{*}=\left[\begin{array}{cccc}
2 \zeta_{1} \omega_{1} & 0 & \cdots & 0 \\
0 & 2 \zeta_{2} \omega_{2} & \cdots & 0 \\
\vdots & \vdots & \ddots & \vdots \\
0 & 0 & \cdots & 2 \zeta_{8} \omega_{8}
\end{array}\right]
\end{aligned}
$$

The collocated sensor and actuator pair for the studies presented here are sited at TP18. The point accelerance FRF of the ROM derived at this location for the controller design is shown in Figure 4. This comprises of the three dominant modes of vibration that are observable at this location within the frequency span 0-25 Hz. Also shown in Figure 4 is the FRF derived from the EMA tests at the same location for comparison. 


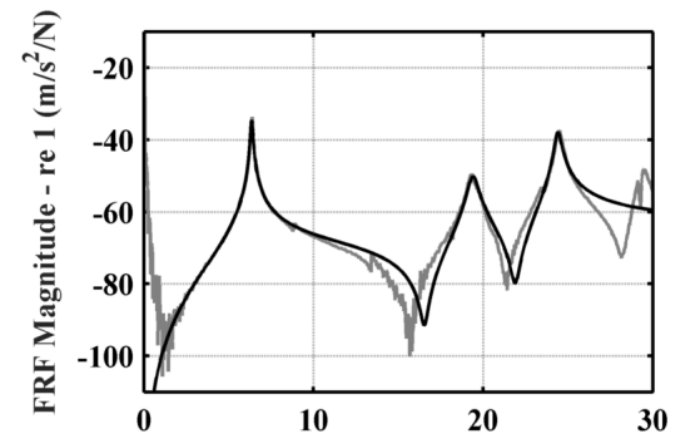

a)

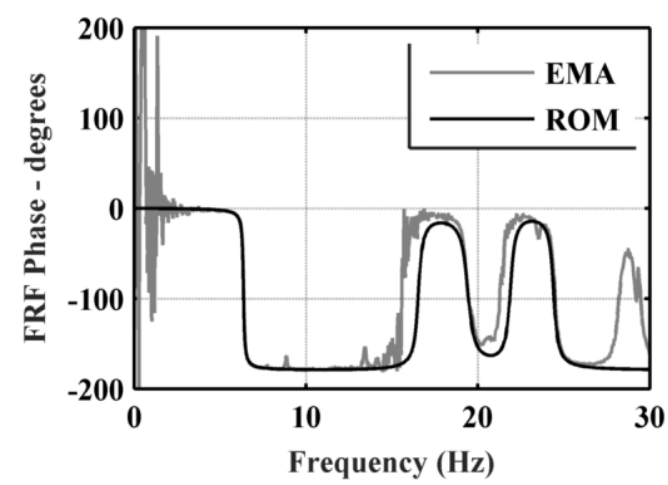

b)

Figure 4. Frequency response function (FRF) magnitudes and phases of EMA measurement and estimated model at TP18.

An overview of the controller scheme for the analytical studies is shown in Figures $5 \mathrm{a}$ and $5 \mathrm{~b}$, and with the set-up in Figure $5 \mathrm{~b}$ highlighting the development of the fuzzy controller scheme. $G_{p}(s), G_{a c t}(s), G_{b p}(s)$ and $G_{n o t}(s)$ represent the floor dynamics, actuator dynamics, band-pass filter and notch filter. $G_{c}(s)$ is the compensator with DVF scheme and $G_{i}(s)$ is an ideal integrator introduced to derive the floor velocity response, i.e. one of the input parameters into the fuzzy controller. $d_{i}(t), y_{a}(t), y_{f}(t)$ and $v_{c}(t)$ are the disturbance input, floor acceleration response, filtered acceleration response and control signal, respectively. $y_{a f}(t)$ and $y_{v f}(t)$ in Figure $5 \mathrm{~b}$ are the filtered floor acceleration and velocity parameters that feed into the fuzzy controller.

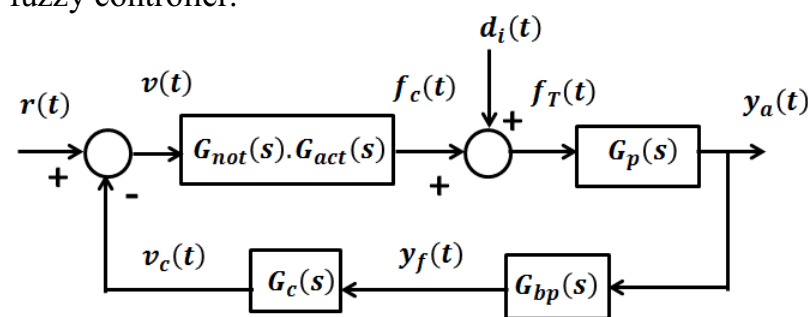

a)

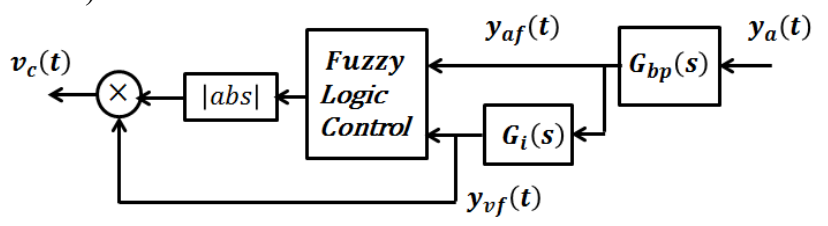

b)

Figure 5. Overview of the controller scheme and set-up with Fuzzy Logic control
$G_{a c t}(s)$ and $G_{n o t}(s)$ are shown in Equations 2 and 3 $K_{a c t}=300 \mathrm{~N} / \mathrm{V}, \zeta_{a c t}=0.1, \omega_{a c t}=8.17 \mathrm{rad} / \mathrm{s}, k_{\text {not }}=10$ and $\zeta_{a c t}=\zeta_{n o t}, \omega_{a c t}=\omega_{n o t}$.

$$
\begin{gathered}
G_{a c t}(s)=\frac{K_{a c t} s^{2}}{s^{2}+2 \zeta_{a c t} \omega_{a c t} s+\omega_{a c t}^{2}} \\
G_{n o t}(s)=\frac{s^{2}+2 \zeta_{n o t} \omega_{n o t} s+\omega_{n o t}^{2}}{s^{2}+2 k_{n o t} \zeta_{n o t} \omega_{n o t} s+\omega_{n o t}^{2}}
\end{gathered}
$$

The optimal DVF controller in Equation 4 results in $K_{g}=220$. This gain meets the required stability limits that consider both the Nyquist contour plot of $G_{c}(s) G_{a c t}(s) G_{n o t}(s) G_{b p}(s) G_{p}(s)$ and a constraint imposed on the actuator mass displacement to disturbance input relationship in Equation 5. $G_{a c t_{-} d}(s)$ is the actuator displacement to disturbance input relationship shown in Equation 6 with $K_{a c t_{-} d}=10$. The relationship in Equation 5 should not exceed $0.05 \mathrm{~mm} / \mathrm{N}$ around the actuator resonant frequency to reduce the potential for stroke saturation. This is found to be the limiting factor in selection of the control gain parameter. Figures $6 \mathrm{a}$ and $6 \mathrm{~b}$ show the Nyquist contour plot of $G_{c}(s) G_{a c t}(s) G_{n o t}(s) G_{b p}(s) G_{p}(s)$ and the relationship in Equation 5.

$$
\begin{gathered}
G_{c}(s)=\frac{K_{g}}{s} \\
Y_{d}(s)=\frac{G_{n o t}(s) G_{a c t_{-} d}(s) G_{c}(s) G_{b p}(s) G_{p}(s)}{1+G_{n o t}(s) G_{a c t_{-} d}(s) G_{c}(s) G_{b p}(s) G_{p}(s)} D_{i}(s) \\
G_{a c t_{-} d}(s)=\frac{K_{a c t_{-} d}}{s^{2}+2 \zeta_{a c t} \omega_{a c t} s+\omega_{a c t}^{2}}
\end{gathered}
$$




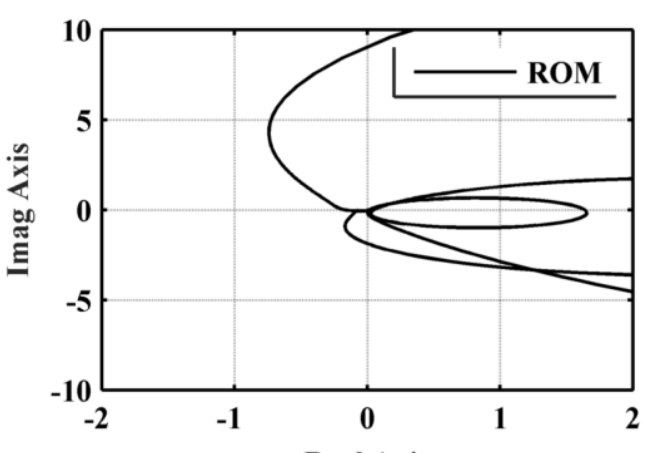

a)

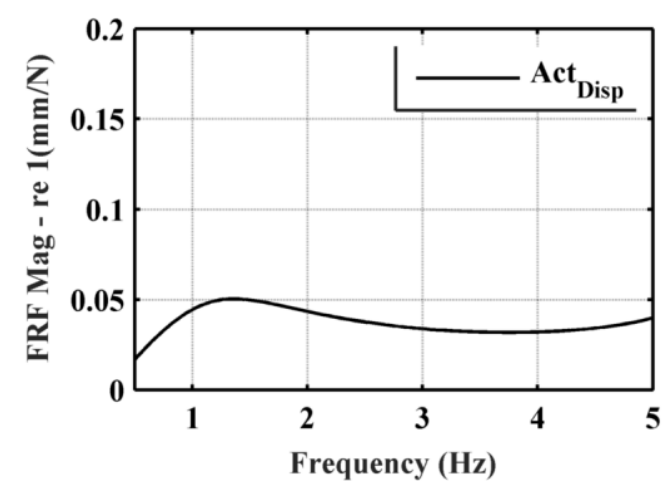

\begin{tabular}{clll} 
b) & \multicolumn{2}{c}{ Frequency (Hz) } \\
igure & (a) Nyquist contour plot of
\end{tabular} $G_{c}(s) G_{a c t}(s) G_{n o t}(s) G_{b p}(s) G_{p}(s)$ and (b) actuator displacement to disturbance input relationship

The steps taken in designing the fuzzy controller in these studies consists of:

1. Selection of input and output variables and their definition

2. Definition of linguistic variables to form a database

3. Establishment of the control rule base

4. Determination of fuzzy inference strategies

5. Selection of defuzzification strategies

The input parameters into the fuzzy controller are the velocity and acceleration responses of the prototype floor. The expected maximum velocity and acceleration response thresholds: $V_{\max }$ and $A_{\max }$ are determined in this work by subjecting the derived reduced order model (ROM) of the floor in Figure 4 to a synthesized walking excitation force that is representative of a pedestrian walking at a pacing frequency of $2.12 \mathrm{~Hz}$. This is then weighted by a factor of 1.5 , i.e. $1.5 \mathrm{~V}_{\max }$ and $1.5 \mathrm{~A}_{\max }$ and these are used to set the range for the velocity and acceleration fuzzy intervals. The velocity and acceleration fuzzy intervals are thus: $[-0.03,0.03]$ and $[-1.2,1.2]$, respectively in the work presented here.

The output of the fuzzy controller is a velocity feedback gain parameter. The thresholds for this are derived based on the feedback gain derived for the DVF controller in this work, i.e. $K_{g}=220$, and this is weighted by a factor of 2.0 to provide $G_{\max }=440$. The fuzzy interval of the velocity feedback gain is thus selected as: [-440,440].

The three linguistic variables, i.e. the velocity, acceleration and velocity feedback gain are each defined by three different linguistic items: Negative $(\mathrm{N})$, Zero $(\mathrm{Z})$, and Positive $(\mathrm{P})$. This is the most basic structure of formulation of the fuzzy logic controller that is used in this work. Typical triangular membership functions developed for each of the linguistic variables are shown in Figures $7 \mathrm{a}, 7 \mathrm{~b}$ and $7 \mathrm{c}$. Iterative studies with different overlap ratios have been performed in this work using a controlled trial and error approach to try and narrow down to parameters that can be regarded as optimal to some degree. In Figure $7,-V_{1} \in\{-0.03,-0.0075,0\}$, $V_{0} \in\{-7.5 e-4,0,7.5 e-4\}, \quad-A_{1} \in\{-1.2,-0.4,0\}$, $A_{0} \in\{-0.1,0,0.1\}$, $-G_{0} \in\{-50,0,50\}$.

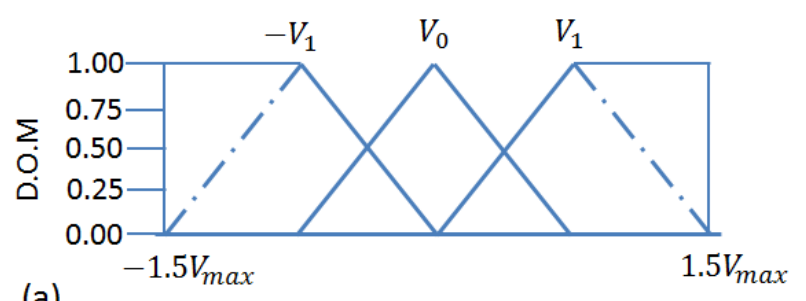

(a)

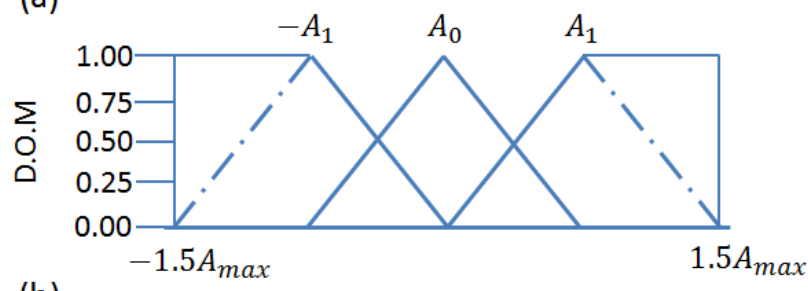

(b)

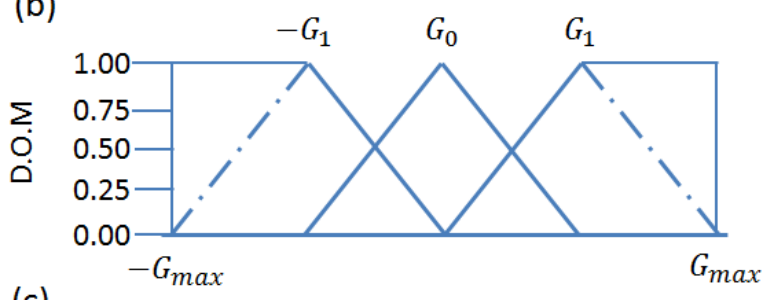

(c)

Figure 7. Triangular membership functions for: (a) velocity,

(b) acceleration and (c) feedback gain linguistic variables

The fuzzy control rules are established in this work as shown in Table 2. $g$ are the gain terms for different error conditions within the fuzzy controller. The fuzzy inference strategy adopted is Zadeh's max-min method.

Table 2. Fuzzy control rules

\begin{tabular}{|c|c|c|c|}
\hline$\ddot{X}$ & $\dot{X}$ & & \\
\hline & $\mathbf{N}$ & $\mathbf{Z}$ & $\mathbf{P}$ \\
\hline $\mathbf{N}$ & $g$ & $-g$ & $-g$ \\
\hline $\mathbf{Z}$ & $g$ & $Z$ & $-g$ \\
\hline $\mathbf{P}$ & $g$ & $g$ & $-g$ \\
\hline
\end{tabular}

The defuzzification strategy adopted is the centroid defuzzification approach. It can be expressed as shown in Equation 7 , in which $x^{*}$ is the defuzzified output, $\mu_{i}(x)$ is the aggregated membership function and $x$ is the output variable. $x$ here can be regarded as the velocity gain term. 


$$
x^{*}=\frac{\int \mu_{i}(x) x d x}{\int \mu_{i}(x) d x}
$$

The Fuzzy controller is developed with the Fuzzy Logic Toolbox in Matlab.

\section{The application of DVF and fuzzy controllers to the floor prototype}

The designed DVF and fuzzy controllers are applied to the prototype floor structure ROM and the following evaluated:

1. Uncontrolled and controlled responses to a synthesized walking excitation force. This synthesized force is applied to the ROM in the sequence of $100 \%, 75 \%, 50 \%$ and $25 \%$ of its original magnitude in order to study vibration mitigation performances between the two controllers.

2. Actuator displacements and forces for both controllers for the above conditions

3. The fuzzy control gains obtained

The synthesized walking force that is used in the analytical studies is shown in Figure 8. This assumes a pedestrian walking at a pacing frequency of $2.12 \mathrm{~Hz}$.

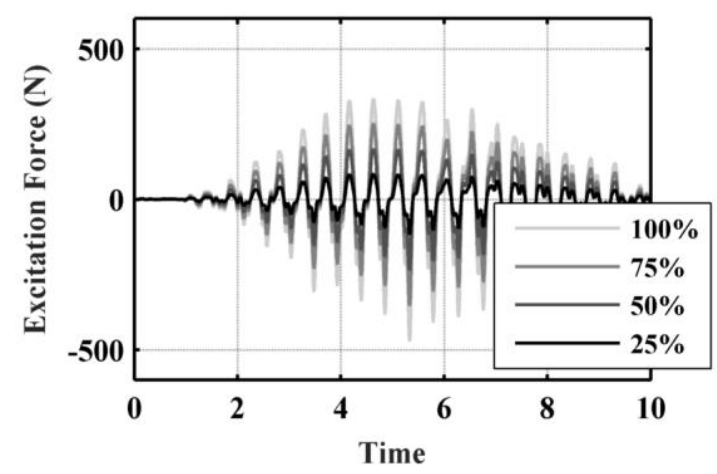

Figure 8. Synthesized walking excitation force

Typical uncontrolled and controlled responses to the synthesized walking excitation force in Figure 8 for $100 \%$ and $25 \%$ levels of the synthesized force are shown in Figures 9a and 10a for responses at TP18. They are considered to be the extreme boundaries in these sets of studies. These have been weighted using the $\mathrm{Wb}$ weighting function [3]. Also shown in Figures 9 and 10 (b-d) are the actuator displacements, typical control forces, and the fuzzy gains.
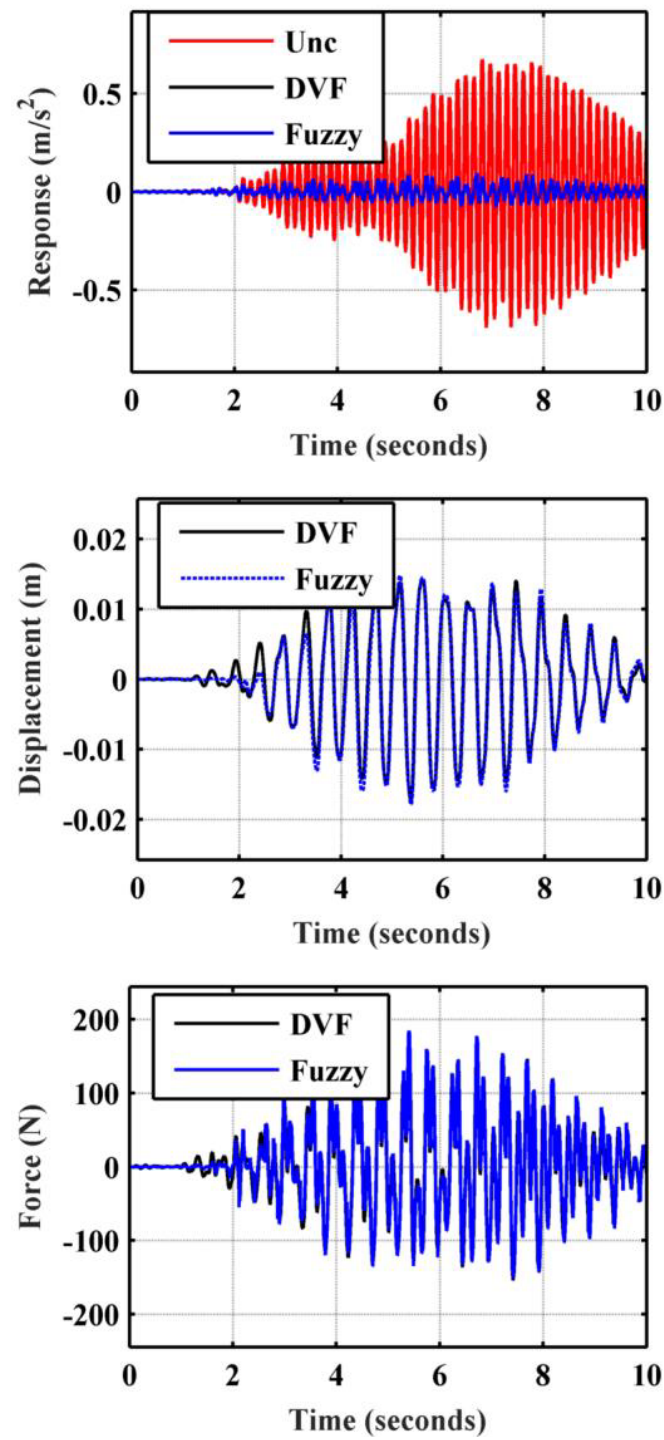

c)

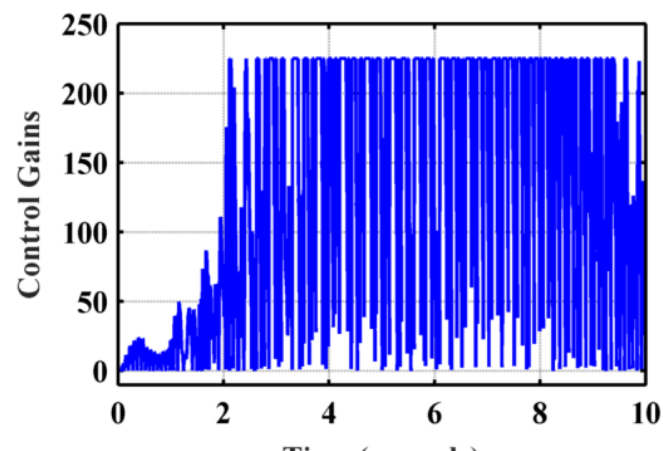

d)

Time (seconds)

Figure 9. (a) Uncontrolled and controlled response to synthesized walking force $(100 \%)$. (b) Actuator displacement. (c) Control forces. (d) Fuzzy gains. 


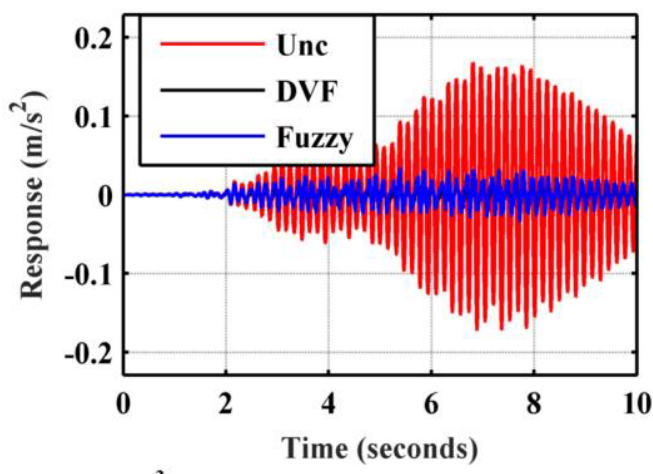

Table 3. Peak of $1 \mathrm{~s}$ running RMS acceleration responses for uncontrolled and controlled studies

\begin{tabular}{|c|c|c|c|}
\hline $\begin{array}{c}\text { Excitation } \\
\text { Level }\end{array}$ & $\begin{array}{c}\text { Uncontrolled } \\
\text { responses }\end{array}$ & \multicolumn{2}{|c|}{ Controlled Responses } \\
\hline & & DVF & $\begin{array}{c}\text { Fuzzy } \\
\text { control } \\
\left(\mathrm{m} / \mathrm{s}^{2}\right)\end{array}$ \\
\hline $100 \%$ & 0.518 & 0.0475 & 0.0483 \\
\hline $75 \%$ & 0.389 & 0.0356 & 0.0374 \\
\hline $50 \%$ & 0.259 & 0.0237 & 0.0277 \\
\hline $25 \%$ & 0.130 & 0.0119 & 0.0188 \\
\hline
\end{tabular}

a)

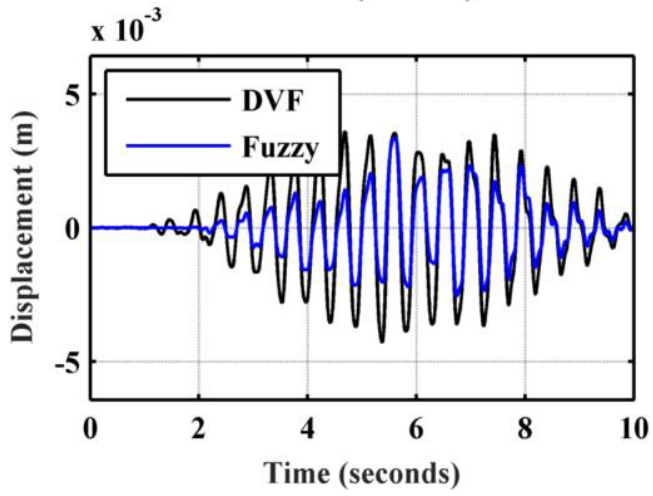

b)

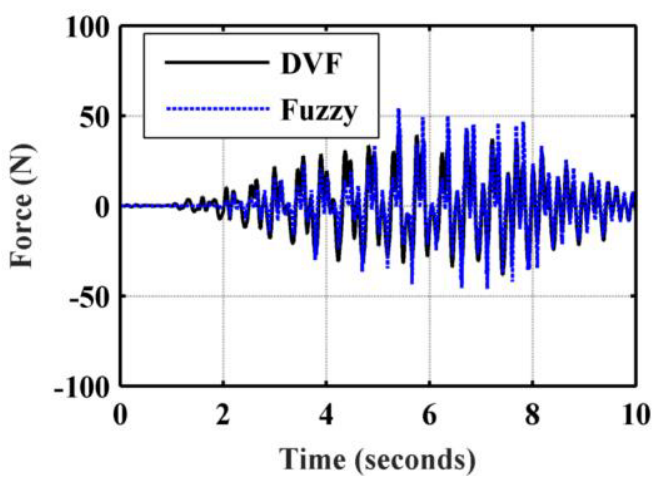

c)

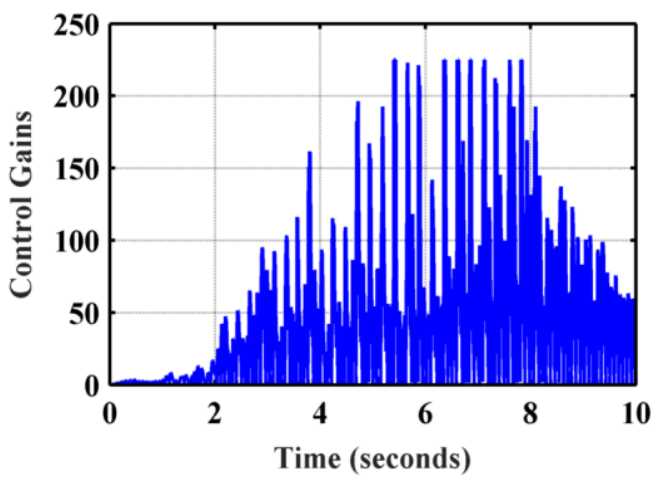

d)

Figure 10. (a) Uncontrolled and controlled response to synthesized walking force (25\%). (b) Actuator displacement. (c) Control forces. (d) Fuzzy gains.

The peaks of the $1 \mathrm{~s}$ running root mean square (RMS) acceleration responses are shown in Table 3. These are defined as the maximum transient vibration value (MTVV) (ISO 2631: 1997).
Some observations can be made from the results of the analytical simulations presented in Figures 9 and 10 and Table 3. For very high responses, consisting of a disturbance input level of $100 \%$ of the synthesized walking excitation force, similar vibration mitigation performances between the DVF controller and the Fuzzy controller can be seen. The control forces and actuator displacements resulting are pretty much similar. It can be seen how the fuzzy gains are saturated for this level of excitation, which would naturally compare with the DVF controller that makes use of a fixed gain parameter.

For moderately low responses, for example, considering a disturbance input level of $25 \%$ of the synthesized walking excitation force, vibration mitigation performances are also identical as seen in Table 3. Some variances in the actuator displacement and control force between the DVF and fuzzy controllers can now be seen. Only in a very small fraction of the overall time does the fuzzy velocity gains get to a saturation limit gain of 220, and thus for this fuzzy control design and case study, at extremely low responses in which no control force is needed, the control gains naturally tend towards zero. This may also have an impact on the control energy at certain response levels.

\section{Conclusions}

The work presented here has looked at comparative studies between the DVF controller and a fuzzy controller scheme that is designed to offer variable velocity feedback gains depending on the structural velocity and acceleration response levels.

For different structural response levels ranging from high responses to low responses that are imposed by variations in the levels of the excitation force, similar vibration mitigation performances between the DVF controller and fuzzy controller sets is seen.

Variances are, however, seen in other controller parameters specifically in the actuator displacement and force characteristics. Under high structural response levels, the fuzzy gains are pretty much saturated to full gain most of the time and thus identical actuator characteristics in the form of the force levels and actuator displacement are seen in both the fuzzy controller and DVF controller. Under lower structural response levels, the fuzzy gains reach saturation at intermittent levels and at a much small fraction of the overall time, and differences can now be seen in the level of control forces as well as the actuator displacement between the fuzzy 
controller and DVF controller. This might have an impact on the running costs of the active control system in the long run.

This study is interesting as these conditions may exist in real-life floor structures that are deemed to be problematic under human excitations. It is seen that the fuzzy control design approach may introduce other design freedoms that require appropriate boundary conditions to be introduced.

\section{Acknowledgements}

The authors would like to acknowledge the financial assistance provided by the UK Engineering and Physical Sciences Research Council (EPSRC) through a responsive mode grant (Ref. EP/H009825/1), a Platform Grant (Ref. EP/G061130/2) and a Leadership Fellowship Grant (Ref. EP/J004081/2). Also acknowledged are the British Council (UK) through the Researcher Links programme and Brazilian institutions CNPq and CAPES financial support.

\section{References}

1. M. Setareh. Vibration serviceability of a buidling floor structure: Dynamic Testing and Computer Modeling, Journal of Performance of Constructed Facilities, 24 (6), 497-507 (2010).

2. J. Brownjohn and A. Pavic. Vibration control of ultra-sensitive facilities, ICE Proceedings: Structures and Buildings, 159, SB5, 295-306 (2006).

3. BS6841:1987. Guide to Measurement and Evaluation of Human Exposure to Whole-Body Mechanical Vibration and Repeated Shock, British Standard.

4. BS6472-1:2008. Guide to evaluation of human exposure to vibration in buildings, Vibration sources other than blasting, British Standard.

5. ISO 10137:2007. (2012). ISO 10137:2007 Bases for design of structures - Serviceability of buildings and walkways against vibrations - reviewed in 2012 (2nd ed.). International Standards Organisation.

6. S.J. Hicks and A.L. Smith. Design of floor structures against human-induced vibrations. Steel Construction, 4(2), 114-120 (2011).

7. I.M. Díaz and P. Reynolds. Acceleration feedback control of human-induced floor vibrations. Engineering Structures, 32(1), 163-173 (2010).

8. L.M. Hanagan and T.M. Murray. (1998). Experimental Implementation of Active Control to Reduce Annoying Floor Vibrations. AISC Engineering Journal, 35(4), 123-127 (1998).

9. D. Nyawako, P. Reynolds and M.J. Hudson. Findings with AVC design for mitigation of human induced vibrations in office floors. In IMAC XXXI. Orange County, CA, USA: Society for Experimental Mechanics (SEM) (2013).

10. I.M. Diaz, E. Pereira, M.J. Hudson and P. Reynolds. Enhancing active vibration control of pedestrian structures using inertial actuators with local feedback control, Engineering Structures, 41, 157166 (2012).

11. G.W. Housner, L.A. Bergman, T.K. Caughey, A.G. Chassiakos, R.O. Claus, S.F. Masri, R.E. Skelton, T.T. Soong, B.F. Spencer and J.T.P Yao. (1997) Structural Control: Past, Present, and Future, Journal of Engineering Mechanics, 123(9), 897-971 (1997).

12. L.A. Zadeh. Fuzzy Sets, Information and Control, 8, 338-353 (1965).

13. T.L. Teng, C.P. Peng and C. Chuang. A study on the application of fuzzy theory to structural active control, Computer Methods in Applied Mechanics and Engineering, 189, 439-448 (2000).

14. G.L.F. Mendonca, S.A. Silva, R.L. Pimentel, C.R. Souto. Automatic directing system for controlling the vibration of frame structures in any horizontal direction using a hybrid mass damper, Journal of Engineering Mechanics (ASCE) 138(8), 915-922.

15. E. Tachibana, Y. Inoue, and B.G. Creamer. Fuzzy theory for the active control of the dynamic response in buildings, Microcomputers in Civil Engineering, 7(3), 179-189 (1992).

16. ISO 2631 (1997) Mechanical vibration and shock evaluation of human exposure to whole body vibration. 